\title{
0 destacamento em aplicativos de notícias e a produção de memória discursiva
}

\section{Érika de Moraes}

\section{Resumo}

Este artigo analisa discursivamente 0 funcionamento da cobertura jornalística em dois aplicativos para dispositivos móveis: um nacional (UOL, vinculado ao grupo Folha) e um internacional (Le Monde). Com o respaldo teórico-metodológico da Análise do Discurso de linha francesa, o objetivo principal é demonstrar como o modo atual de circulação de notícias produz efeitos sobre os registros que se cristalizam na memória discursiva. 0s dados analisados demonstram que as características da discursividade contemporânea, com ênfase no destacamento, contribuem para a produção de memórias fragmentadas, ainda assim com certo controle por parte da mídia.

\section{Palavras-Chave}

Aplicativos. Destacamento. Memória Discursiva.

\section{Érika de Moraes}

Doutor em Linguística pela Universidade Estadual de Campinas, Brasil. Professor Assistente da Universidade Estadual Paulista Júlio de Mesquita Filho, UNESP, Campus de Bauru, São Paulo, Brasil. E-mail: erika.moraes@unesp.br https://orcid.org/0000-0002-6571-3971

\section{Introdução}

Este artigo compila dados de uma pesquisa mais ampla, cujo objetivo foi analisar discursivamente o funcionamento da cobertura jornalística sobre o Brasil, especialmente em aplicativos para dispositivos móveis. Foram selecionados dois aplicativos, um nacional (o UOL, vinculado ao grupo Folha) e um internacional (o francês Le Monde), ambos escolhidos pela abrangência e relevância nacional e internacional, respectivamente.

A opção por aplicativos para dispositivos móveis não é aleatória; ao contrário, justifica-se pelas características de leitura na era da informação digital $^{1}$, conforme explicitaremos no decorrer deste artigo. 0 corpus sobre o Brasil foi uma opção temática que nos permitiu, entre os objetivos da pesquisa como um todo, investigar a imagem do Brasil que se fixa internacionalmente a partir da cobertura da mídia. Porém, mais do que constatar estereótipos sobre o Brasil, o objetivo era compreender e demonstrar como o modo de funcionamento da mídia produz efeitos sobre os registros que se cristalizam na memória discursiva. 
Nossas análises são respaldadas pelo quadro teórico-conceitual da Análise do Discurso francesa, linha desenvolvida por Pêcheux na década de 1960 e em constante processo de atualização, a partir do trabalho de autores contemporâneos como Maingueneau; Paveau; Krieg-Planque, Angermuller (na França); Possenti, Orlandi e diversos círculos de estudo no Brasil, país em que encontrou terreno fértil para se ressignificar. Ainda que as abordagens desses e de outros autores possam enfatizar diferentes aspectos, compartilham de um quadro conceitual comum, segundo o qual o discurso é atravessado pelo interdiscurso, imbuído de ideologia e influenciado pelo inconsciente. Existe um "sempre-já-dito" intrínseco a todo e qualquer discurso, correlato aos lugares ideológicos em que se situam os sujeitos que se colocam como responsáveis por tais discursos.

Não desconsideramos a existência de pesquisa qualificada no Brasil e em países vizinhos sobre 0 ciberjornalismo. Sabemos, também, que a inovação em jornalismo é bastante frutífera na América Latina, conforme demonstra, por exemplo, o trabalho editado por Mioli e Nafría (2017), que retrata a efervescência de sites de notícias, realidade virtual, empreendedorismo. A opção por abordar apenas dois aplicativos de notícias específicos, um brasileiro e um europeu, justifica-se pela necessidade de recorte a fim de priorizar a discussão em torno da interdiscursividade no atual universo de narratividade jornalística, o que pretende ser a contribuição deste trabalho.

Por razões de delimitação, enfatizamos 0 olhar discursivo para a materialidade da língua e do suporte, com ênfase na contribuição de conceitos propostos por Dominique Maingueneau. Os elementos de destaque do jornalismo (títulos, linhas finas, olhos, legendas etc.), também compreendidos como apelos verbais e visuais (MEDINA, 1988), podem ser refletidos à luz das noções de destacamento e detacabilidade, tais quais elaboradas por Maingueneau (2006, 2010, 2014). 0 autor parte dos destacamentos para mostrar que determinadas frases seriam produzidas com uma convicção diante do mundo, que se apresenta como rica de sentido para todos, o que o leva ao conceito de aforizaçãa (do qual tratamos em MORAES, 2016). 0 enunciado aforizante, pautado numa simulação de verdade advinda de uma voz superior, sustentada por um discurso alhures, funciona ao mesmo tempo como memorável e memorizável. Os destacamentos têm papel relevante na narratividade jornalística, com potencial aforizante, portanto, rico na constituição de memória.

Resende (2009) busca compreender o discurso jornalístico com base em sua narratividade, 
concebida em confronto com o paradoxo da incomunicabilidade (Ricoer, 2005) e sobre cujas brechas dar-se-ia "a possibilidade do encontro", ou seja, de um fio condutor comunicativo apesar da opacidade da linguagem. Para comunicar, de certo modo, dribla-se com a não transparência da linguagem, com a polissemia e, sobretudo, em termos discursivos, com a interincompreensão latente ao fato de que os discursos advêm de lugares ideológicos: "não há dissociação entre $o$ fato de enunciar em conformidade com as regras de sua própria formação discursiva e de 'não compreender' o sentido dos enunciados do Outro, são duas facetas do mesmo fenômeno" (MAINGUENEAU, 2005, p. 103). 0 discurso jornalístico teria o papel transgressor, no sentido de Ricoeur, ao buscar possibilitar a comunicabilidade. Amparado em Ricoeur, para quem sentidos e forças são constitutivos do mundo em movimento, Resende defende que "é na dimensão do simbólico que tal natureza atua" sendo então "na inscrição da linguagem que se deve buscar compreender as faltas" (RESENDE, 2009, p. 33), o que 0 autor propõe fazer por meio da atenção minuciosa à narratividade do texto jornalístico, compreendida como lugar de produção do conhecimento: "0 ato de narrar, através dos meios, pode revelar legitimações, valores, representações e faltas, dados

preponderantes para 0 processo de compreensão e leitura do mundo" (ibid.).

Ao priorizar o estudo dos destacamentos, em especial dos títulos, busca-se compreender como se constrói, discursivamente, a relevância de tais destaques para o público. Os títulos e demais destaques são em si uma forma alternativa da narratividade, funcionando como pontos luminosos da tessitura do texto jornalístico: há uma história que se conta por meio do destacamento, uma (outra) história (mais) fragmentada.

Em nosso relatório (MORAES, 2017), apresentamos uma amostragem representativa de análises comparativas de notícias equivalentes, divulgadas nos aplicativos estudados. 0 contato imersivo com o corpus permitiu aprofundar as hipóteses sobre o destacamento midiático e sua relação com a construção de memória discursiva. É desse aspecto que tratamos neste artigo, visando à necessidade constante de refinar uma metodologia para analisar o discurso da imprensa. Para tanto, recorremos à mobilização analítica de dados de nosso corpus $^{2}$, tratando dos efeitos de sentidos na materialidade discursiva do material, em em evidência o nosso país e não em um tipo de discurso específico (o político, por exemplo). Como pondera Angermuller, há desafios para a constituição de um corpus de pesquisa, já que "0 discurso não tem fronteiras interiores ou exteriores estáveis" (ANGERMULLER, 2016, p. 32). 0 corpus abrange a cobertura dos aplicativos UOL e Le Monde no período de dezembro de 2015 a junho de 2017. Tal período compreende a repercussão do impeachment da Presidente Dilma Rousseff em 2016, desdobramentos da operação Lava Jato, novas manifestações em 2017. Assim, embora a política não tenha sido uma delimitação, é inevitável que o assunto seja recorrente no material analisado. É desse corpus mais amplo que ora apresentamos recortes de dados para demonstração de alguns resultados da pesquisa. 
busca de descrever um modo de funcionamento

do jornalismo contemporâneo, substanciado na potencialização dos destaques, e como esse funcionamento, reciprocamente, afeta a sua própria materialidade.

\section{Analisar o discurso midiático}

A escolha pelo estudo dos aplicativos de notícias, conectada com a contemporaneidade, não desconsidera que esses aplicativos se vinculam a nomes próprios de veículos jornalísticos pautados em linhas editoriais específicas. É, sobretudo, de cobertura jornalística de porte internacional que se trata. Esse vínculo dos aplicativos com os nomes próprios de grupos jornalísticos fortalece 0 efeito de credibilidade atribuído aos meios tradicionalmente impressos. 0 termo "impresso", aqui, deve então ser entendido em amplo sentido, relacionado ao registro do escrito, independentemente de seu suporte físico.

Ao contrário de substituir o jornalismo impresso, as mídias digitais permitiram a sua revalorização como mídia de atualidade quente, com 0 advento dos jornais on-line. Nas palavras de Ringoot, "por tempos, destronada pelas mídias audiovisuais, pelo que concerne a rapidez e imediatismo da informação, a imprensa pode então rivalizar nesse terreno, desde que ela se desenvolveu na Internet" (2014, p. 85, tradução nossa) ${ }^{3}$. Ainda dialogando com Ringoot, a imprensa (escrita) é a que detém o maior peso, a fim de se apreender notadamente como uma informação, entre todas no fio da atualidade, pode se tornar elegível para um tratamento mais consequente. Ou seja, a imprensa alcança um novo status outrora perdido para os meios audiovisuais (0 imediatismo, conquistado com a possibilidade de atualizar conteúdos on-line e ser reposicionada como "imprensa quente") e ainda reforça o seu anterior, o de aprofundamento, aspecto em que sempre foi soberana. Isso considerado, é preciso acrescentar que a imprensa é afetada pelas características da comunicação digital e pela maximização da leitura scanner, realizada por aqueles "que certamente vão procurar resumos de informação, preferem blocos de textos de até 100 palavras" (MOHERDAUI, 2007, p. 199) ${ }^{4}$.

Conforme apontam Canavilhas e Satufi (2015), com os novos dispositivos, os meios de comunicação acordam para uma nova realidade, especialmente com as apostas nas aplicações para iOS e Android. Para os autores, "as características técnicas dos dispositivos 
de consumo são um elemento fundamental na definição das narrativas jornalísticas" além de representarem um "fator de diferenciação intermediático e uma janela de oportunidade para a afirmação dos novos meios face aos tradicionais" (CANAVILHAS E SATUFI, 2015, p. 2). Nosso objetivo, pelo olhar discursivo, é propor um debate complementar: como o jornalismo, ao adaptar-se aos novos caminhos potencializados pelos dispositivos móveis, interfere, por meio dos novos modos de narratividade, na configuração (inter)discursiva de memória.

Seja em papel ou desmaterializada na web, a imprensa se mantém e se renova, sendo relevante compreender o seu funcionamento discursivo.

0 lugar ocupado por uma notícia em seu suporte físico (a capa do jornal, a homepage ou a posição de destaque no aplicativo) é tão importante quanto o conteúdo por ele vinculado e, em termos discursivos, delimita uma cena de enunciação.

Ao estudar o funcionamento midiático de um ponto de vista discursivo, Ringoot (2014) sinaliza a importância de se levar em conta 'qui' parle e comment, ou seja, quem fala e como, em termos de posicionamento. No caso do jornalismo, deve-se ter em vista que tal processo de enunciação se dá a partir de um quadro editorial, substanciado na deontologia da profissão, na imagem institucional do veículo, entre outros aspectos. 0 funcionamento do jornalismo em si reforça o vínculo de reciprocidade entre quem fala e como se fala, já que todo o modo de escrita jornalístico se dá por uma construção de efeito de credibilidade. Assim, ao analisar o discurso jornalístico, é pertinente considerar, de maneira entrelaçada, tanto o acontecimento retratado quanto as suas modalidades de construção. Nesse aspecto, conforme sinaliza Ringoot, os títulos são elementos cruciais do jornalismo porque cristalizam a construção do acontecimento (2014, p. 6).

0 jornalismo tem uma forma específica de se apropriar da linguagem e da língua (RADUTGAGHI, 2017) por meio de um modo de dizer, do qual faz parte um conjunto de técnicas de levantamento da informação (apuração, investigação de dados, entrevistas etc.) e um modo de escrita (redação e edição) pautado em textos preferencialmente "objetivos", iniciados com Lead (respostas às perguntas quem, o quê, quando, onde, como, por quê?), formatados com títulos, linhas finas, subtítulos, olhos.

A existência desses procedimentos funciona como garantidora de credibilidade. Em outras palavras, a credibilidade jornalística é assegurada pelas técnicas que o constituem, enquanto essas técnicas são discursivamente construídas como legitimadoras, ou seja, são a causa e o efeito do discurso jornalístico. A imprensa constrói e retrata o acontecimento, assim como constrói o seu modo de dizer.

Maingueneau expõe que a fala jornalística depende da crise, já que é de crise, do que foge 
ao convencional, ou é desestabilizador, que trata o jornalismo. Diante da necessidade de noticiar, o jornalismo busca a crise, fundamentandose, assim, em um discurso que "fabrica a crise (filosófica, política...) e se legitima ao fabricá-la" (MAINGUENEAU, 2017).

0 funcionamento contemporâneo da mídia, caracterizado por um "excesso de informação", é tal que favorece a leitura de títulos como "listas" de notícias que se misturam e proporcionam a sensação de estar informado sobre tudo $0^{5}$, já que uma característica preliminar do app de notícias é a de ser um meio informativo de checagem rápida, "como uma rede social de conteúdos jornalísticos, onde há um 'feed' ou 'timeline' de notícias dispostas em manchetes curtas" (BERTOCCHI; CAMARGO; SILVEIRA, 2015, p. 73). As matérias mais longas permanecem disponíveis, mas o usuário tem a liberdade de clicar para acessá-las ou de "entender 0 assunto através dos 'bullets' da capa do app, onde uma espécie de grande Lide responde [a] perguntas básicas que dão condições mínimas de compreender o que está acontecendo, qual 0 assunto e a gravidade dele" (idem, p. 73) ${ }^{6}$.
Para Ringoot, analisar a imprensa implica avaliar a especificidade do discurso jornalístico e a maneira pela qual ele se distingue de outros discursos sociais. Esta dimensão é, segundo a autora, fundamental, porque é exatamente aí que se dá a identidade discursiva do jornalismo, sua capacidade de se legitimar e garantir um posicionamento específico. Caso contrário, ele se dilui em outras enunciações e perde sua credibilidade (RING00T, 2014, p. 9).

Ao considerar a realidade das novas tecnologias, defende-se que elas não são a priori as responsáveis pelo funcionamento do jornalismo pautado em destacamentos, mas potencializam esse modo de funcionar já característico da máquina midiática. Nas palavras de Ringoot (2014), artigos e notícias são "atomizados" de modo a serem referenciados: "enviar a um amigo", “dar um like", escrever comentários. "Esses textos podem circular sem cotextos, mas, em contrapartida, são identificados, carimbados pela marca do jornal" (2014, p. 4-5, tradução nossa)?

Com base nessas considerações, propõe-se aqui a atenção a esse funcionamento ao

Paradoxalmente, a lacuna sentida pelo aprofundamento de informação (que, antigamente, costumava ser associada ao jornalismo impresso em contraponto ao audiovisual) tem levado a mídia a caminhar na produção dos chamados webdocs, ainda raros, como aponta Ringoot (2014). A autora anota, como elemento marcante dos últimos anos, a presença de vídeos nos jornais on-line, o que é recorrente nos aplicativos com os quais trabalhamos. 0 que chamamos "feed de destaques" mescla as "listas" de notícias nos moldes do impresso (com predominância do verbal e do icônico) à oferta de vídeos, que constituem um fator de diferenciação dos aplicativos em relação aos jornais impressos a ele correspondentes.

6 Neste trecho, as autoras tratam do aplicativo NYTimes Now, mas as características são transponíveis para os materiais por nós analisados.

No original: "Ces textes peuvent circuler sans cotextes, mais ils sont en revanche identifiés, estampillés par la marque du jornal." 
modo de listas de notícias, característico da comunicação contemporânea. Nossa pesquisa mostra que os destacamentos editam um modo de dizer e direcionam a leitura, a interação e a consequente cristalização de sentidos. Nossas análises mostraram que, embora a leitura da reportagem completa proporcione acesso a detalhes, 0 conjunto do texto em geral não contradiz a leitura scanner dos elementos destacados, quase sempre a confirma ${ }^{8}$. 0 s textos completos, no entanto, precisam estar ali como garantidores da legitimidade dos elementos destacados e, de fato, mobilizam esforços por parte da produção jornalística.

Independentemente das críticas que possam ser feitas à profissão, há uma classe de profissionais que, dia e noite, trabalha com uma série de cruzamento de dados e fontes. Apura, escreve e edita, cumprindo as etapas necessárias para que a divulgação possa ser legitimada pelo nome de um jornal. É por isso que os aplicativos considerados de maior credibilidade são aqueles vinculados a redações jornalísticas de tradição (como o grupo Folha ou Le Monde). Há todo um trabalho que dá suporte ao que pode ser consumido como feed de notícias ou "listas de informações", do qual o público nem sempre tem a dimensão e, ao mesmo tempo, é esse trabalho que sustenta 0 efeito de estar informado mesmo sem ter lido a notícia na íntegra.
Mais do que uma interpretação informal da leitura scanner na rolagem dos dispositivos móveis, o que aqui chamamos de "listas de informações" tem relação com o funcionamento discursivo impactado pela potencialização dos destacamentos. No caso de nosso corpus, que privilegia um recorte de notícias que tematizam a respeito do Brasil, o destaque de tais notícias circula entremeado por assuntos de diversas outras ordens, o que enfatiza um efeito de colagem dos acontecimentos contemporâneos, como se constar da lista fosse garantia de ser acontecimento. Propomos falar, então, defeed de destaques. Discursivamente, os destaques dão tom e corporalidade (MAINGUENEAU, 2000), carregam pontos de vista constitutivos de fragmentos de memória.

\section{Brasil no feed de destaques dos aplicativos}

Nosso recorte adotou a seguinte metodologia: iniciamos a seleção pelo aplicativo francês, por entender que a imprensa estrangeira (em relação ao Brasil) noticia os fatos sobre 0 Brasil considerados de maior impacto internacional. Buscamos, então, notícia(s) equivalente(s) no mesmo período (ou aproximado) no aplicativo brasileiro. Neste artigo, priorizamos um período peculiar, em que a ênfase nas eleições francesas, em Le Monde, por hipótese, reforça 
a característica de que assuntos internacionais precisariam ter grande impacto para obter espaço na mídia então mais focada nas eleições locais.

A fim de compreender melhor as condições de produção (PÊCHEUX, 1990) de tal cobertura, realizamos uma entrevista com o médiateur ${ }^{9} \mathrm{de}$ Le Monde, Franck Nouchi. Salientamos que o ponto de vista oficial do jornal, expresso por meio de seu médiateur, é para nós uma informação importante, mas não suficiente, já que deve ser cruzado com a mobilização de conceitos da Análise do Discurso.

Em primeiro lugar, deve ser considerado que a proposta de Le Monde, segundo confirma seu médiateur, é a de ser um veículo internacional, daí o seu nome "Mundo". Assim, pautar 0 Brasil, bem como outros países, é parte da política editorial do veículo ${ }^{10}$. Conforme explica o médiateur, há dois jornalistas correspondentes no Brasil (um permanente e um substituto), sendo a permanente, Claire Gatinois, especializada em economia, o que significaria, segundo o próprio porta-voz do jornal, que a economia (diretamente relacionada à política) do país, por ocupar um lugar relevante na América do Sul, seria de interesse para o leitor do veículo.
Em maio de 2017, as eleiç̃̃es para a Presidência da República na França foram, por razões evidentes, o principal assunto veiculado pelo aplicativo Le Monde, já que o segundo turno entre os candidatos Emmanuel Macron e Marine Le Pen ocorreria no domingo 07 de maio. Mesmo assim, e por ossos do ofício, assuntos variados, seja sobre 0 Brasil ou outros diversos, estiveram presentes na mídia francesa na semana préeleitoral. Precisamente no dia 05 de maio de 2017, 0 aplicativo veiculou três notícias sobre o Brasil, em meio ao "conjunto jornalístico" no qual sobressaíam as eleições francesas. Conforme podemos observar a seguir, a Figura 1 mostra manchetes sobre os presidenciáveis franceses. A Figura 2 mostra que o conjunto de notícias destaca uma manchete sobre a seca no Brasil, seguida por outra relacionada às presidenciais francesas e outra sobre astronomia. A figura 3 mostra manchete sobre preocupação da $0 \mathrm{NU}$ com um suposto ataque a índios no Brasil (A ONU se alarma com um ataque a uma tribo indígena por proprietários de terra no Brasil, tradução nossa ${ }^{11}$ ), seguida por outros assuntos diversos, e ainda outra notícia sobre 0 Brasil, a respeito da condenação pela justiça brasileira de

Optamos por manter a terminologia original médiateur, pois se trata de uma função diferenciada em relação às existentes nas redações brasileiras, aproximada à do ombudsman, um responsável pela "mediação" com leitores do jornal e pela (auto) avaliação crítica do veículo. Trata-se de profissional com ampla experiência jornalística, que exerceu por mais de quinze anos a função de redator-chefe, responsável pela coerência editorial do veículo e, na prática, pela conferência de títulos e produção de manchetes de capa (la Une).

10 Le Monde possui uma ampla rede de correspondentes internacionais, com quatro escritórios nos Estados Unidos e outros espalhados em todo o globo. A decisão de ter um correspondente fixo em um país depende da relevância da cobertura $\mathrm{e}$ também de condições propícias. 
Figura 1: Manchetes Aplicativo Le Monde

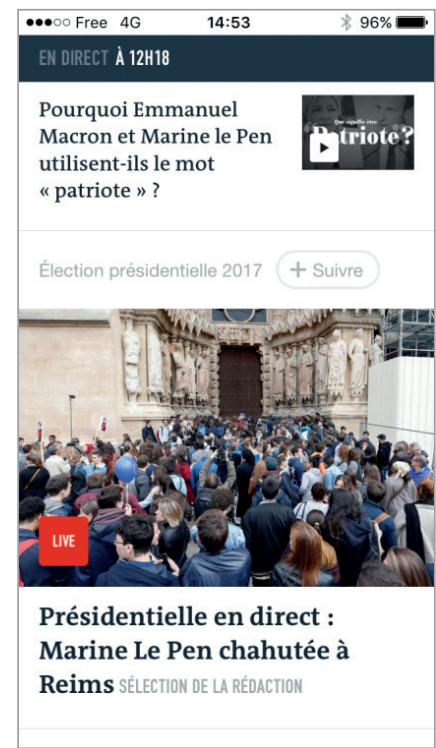

Fonte: Aplicativo Le Monde (Prnt Scrn gerado pela autora)

Figura 2: Manchetes Aplicativo Le Monde

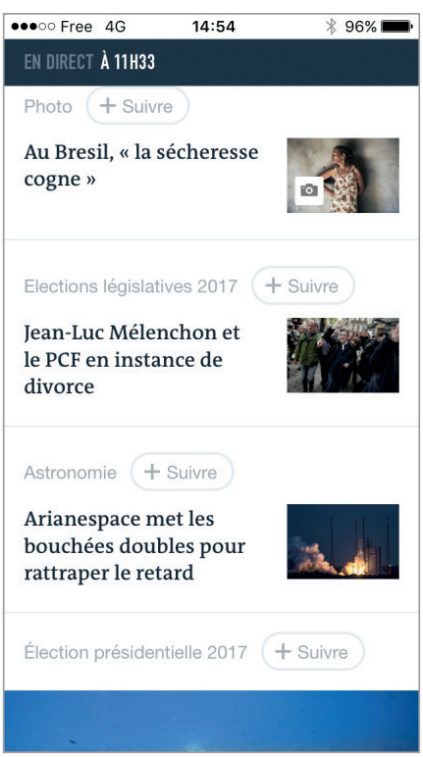

Fonte: Aplicativo Le Monde (Prnt Scrn gerado pela autora)
Figura 3: Manchetes Aplicativo Le Monde

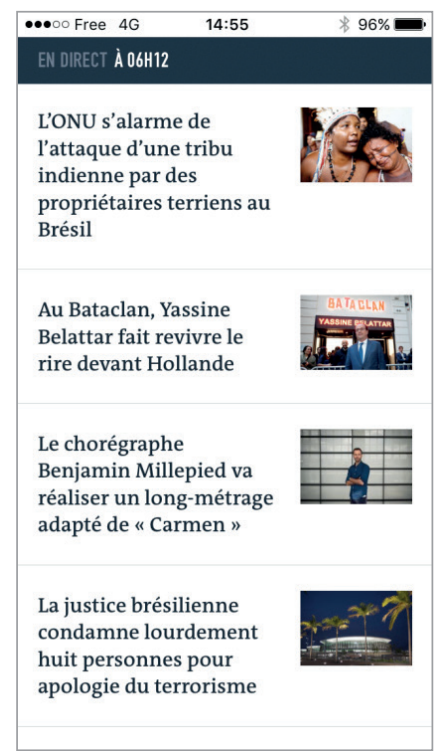

Fonte: Aplicativo Le Monde (Prnt Scrn gerado pela autora)

oito pessoas por apologia ao terrorismo na ocasião dos jogos olímpicos (A justiça brasileira condena duramente oito pessoas por apologia ao terrorismo ${ }^{12}$ ).

Mesmo que tais assuntos possam não ser prioritários para parte dos leitores do aplicativo/jornal, o fato de estarem presentes no feed de destaques dos apps ${ }^{13}$ os constitui como acontecimentos para esses leitores, assim como os demais temas presentes, sejam aqueles relacionados às eleições francesas, ou à editoria de cultura, a exemplo de manchete sobre o coreógrafo Benjamin 
Millepied. Como contrapartida, outros assuntos não pautados por essa mídia não acontecem para 0 seu leitor.

0 usuário que acessa a matéria sobre a seca, ao clicar na chamada, depara-se com outra importante forma destacada de informação, a fotografia, cujo efeito é potencializado pelo fato de esta matéria ser trabalhada em formato de gráfico digital, no qual se clicam nas abas para acessar as imagens. A aba 1 enfatiza o Nordeste como a região mais afetada pela seca, conforme mostra a Figura 4. As abas seguintes, sucessivamente, enfatizam diferentes cidades.

\section{Figura 4: Manchetes Aplicativo Le Monde}

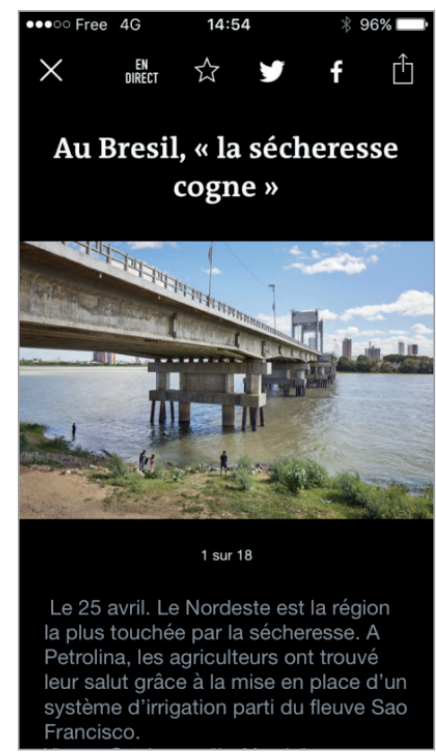

Fonte: Aplicativo Le Monde (Prnt Scrn gerado pela autora)
Figura 5: Imagem destacada na matéria sobre índios do Brasil em Le Monde

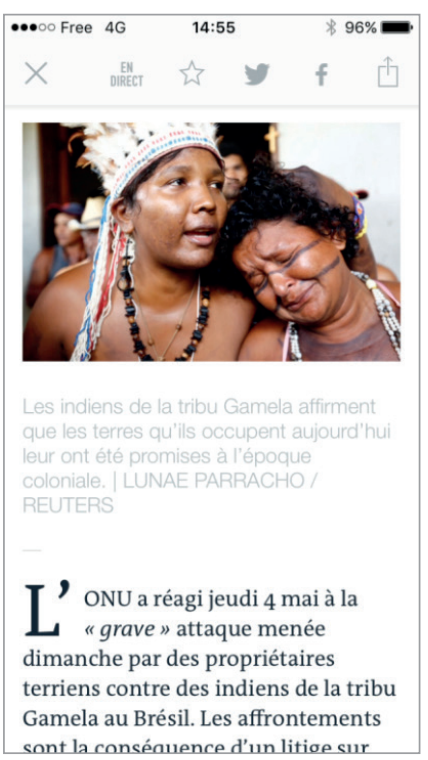

Fonte: Aplicativo Le Monde (Prnt Scrn gerado pela autora)

A matéria sobre 0 ataque a índios também impacta pela fotografia, ao enfatizar os rostos ("a parte nobre do corpo", como expressa Maingueneau, 2010, ao tratar da aforização) de pessoas caracterizadas como indígenas, havendo uma senhora com a expressão facial de choro e expressão corporal de quem busca consolo (apoia no ombro do outro), denotando fragilidade, como mostra a figura 5 .

No mesmo período, a imprensa brasileira, por sua vez, priorizou seus assuntos locais, com

13 As telas dos apps podem ser compreendidas como metáfora de cards (Pietrazk, 2014 apud Mello et. Al., 2015, p. 90) que variam conforme o modelo do aparelho, mas mantêm características semelhantes: forma retangular, dimensões relativamente pequenas, presença de informação. Trata-se, porém, de tela em movimento, que pode ser manuseada individualmente e, paradoxalmente, imobilizada para arquivamento por meio do Prnt Scrn. 0 Prnt Scrn foi a técnica utilizada para arquivamento de dados de nosso corpus. Optamos por privilegiar o celular, por ser atualmente 0 aparelho mais usual. Para os objetivos de nosso trabalho, não são fundamentais as especificações técnicas do aparelho. 
Figura 6: Manchetes Aplicativo UOL

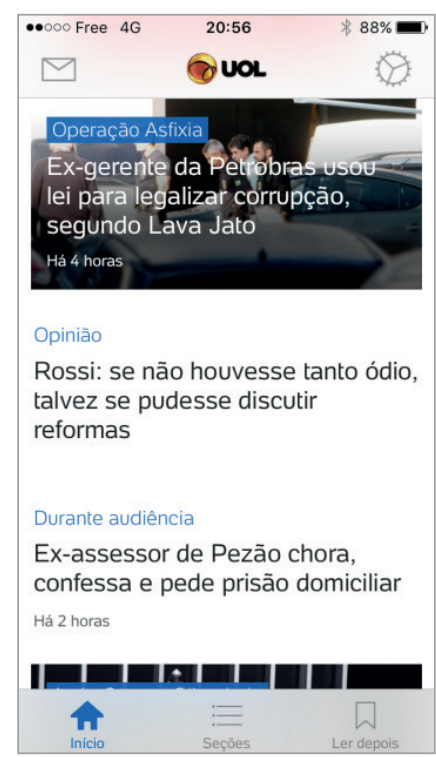

Fonte: Aplicativo UOL (Prnt Scrn gerado pela autora)

Figura 7: Manchetes Aplicativo Le Monde

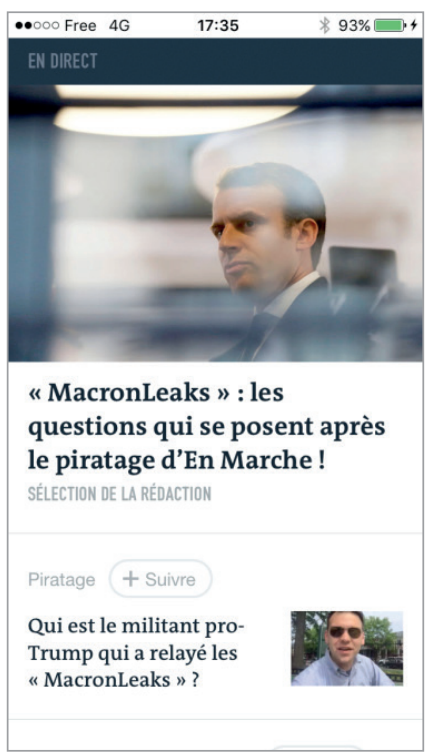

Fonte: Aplicativo Le Monde (Prnt Scrn gerado pela autora) maior ênfase aos desdobramentos da Operação

Lava Jato, tema que visivelmente ocupava 0 maior espaço e tempo da mídia no Brasil, em proporção semelhante à cobertura das eleições para a mídia francesa. Da mesma forma, assuntos sobre a Lava Jato são entremeados por outros de ordens diversas. A figura 6 apresenta algumas das manchetes relacionadas ao Escândalo Petrobras, corrupção e reformas, que circularam no aplicativo UOL do dia 04/05/2017.

No dia 06/05/2017, vésperas das eleições francesas, 0 depoimento de Lula no Brasil encontra espaço em Le Monde, entremeado essencialmente pelos temas relacionados ao segundo turno na França, como mostram a Figura 7 (ênfase no caso "MacronLeaks") e 8, com destaque para o título: "Um antigo diretor da Petrobras coloca diretamente em causa 0 ex-presidente Lula" (tradução nossa) ${ }^{14}$.

Não se trata de um lugar especial dedicado ao Brasil no veículo francês em questão, trata-se de considerar o que é ou deixa de ser notícia em nível internacional. As recorrentes manifestações na Venezuela, por exemplo, também figuram com frequência nas páginas de Le Monde nesse período.

Ainda no que diz respeito ao Brasil, no dia 16/05/2017, entre a predominância de notícias sobre o novo governo Macron, então eleito, 
o aplicativo Le Monde destacou dois temas brasileiros: 1) No Brasil, primeiro ano difícil para o Presidente Michel Temer (tradução nossa) ${ }^{15}$; 2) No Brasil, o recuo massivo da epidemia de Zika é um enigma (tradução nossa) ${ }^{16}$. 0 tema sobre o primeiro ano do governo Temer, por interesse local, é fortemente coberto pela mídia brasileira. Já o tema do Zika vírus ocupou menos espaço na mídia nacional no período em questão, desde o recuo da epidemia - recuo caracterizado pela matéria de Le Monde como um "enigma". No mesmo dia ou em período aproximado, 0 tema não foi notícia no aplicativo UOL/Folha de S. Paulo.

Figura 8: Manchetes Aplicativo Le Monde

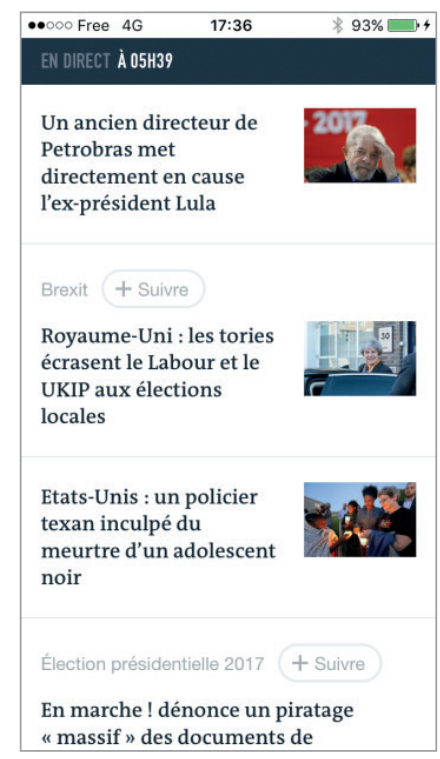

Fonte: Aplicativo Le Monde (Prnt Scrn gerado pela autora)
0 dia 18/05/2017 foi bastante intenso para a política brasileira e, consequentemente, para a cobertura midiática desta editoria. Novas denúncias da operação Lava Jato expõem os nomes do senador Aécio Neves e do Presidente da República Michel Temer, o que faz com que 0 assunto seja predominante na mídia brasileira em geral e no aplicativo UOL em particular. 0 aplicativo Le Monde, entre suas chamadas, traz uma matéria que contextualiza o leitor sobre os acontecimentos no Brasil: "No Brasil, o presidente Temer 'manchado' com novas revelações" (tradução nossa) ${ }^{17}$.

Com a cobertura em tempo real pelas mídias digitais, as "listas" são infindáveis, e as possibilidades de análises, por sua vez, inesgotáveis. 0 que se enfatiza aqui é um fazer jornalístico que, ao tratar do acontecimento, constrói 0 acontecimento em si, agora de maneira mais fragmentada, já que ele só existe para o público que a ele tem acesso e, no contexto atual, de uma forma imediata e com diferenças entre leitores, a depender do horário que 0 usuário teve para acessar o app. Num tempo em que as pessoas informam-se substancialmente on-line, sobretudo por dispositivos móveis, especialmente pelo celular, figurar ou não em posição de destaque na lista é essencial para ser

15 No original: "Au Brésil, première année difficile pour le président Michel Temer".

16 No original: "Au Brésil, le recul massif de l'épidémie de Zika est une énigme".

17 No original: "Au Brésil, le président Temer éclaboussé par de nouvelles révélations". 
acontecimento. Há acontecimentos privilegiados, que se mantêm em posição inicial da rolagem e alguns, inclusive, merecem o disparo de alertas. No entanto, não basta haver uma lista, é preciso que a matéria completa possa ser acessada pelo usuário, que o seu link possa ser compartilhado em mídias sociais, que possa obter "likes" dos amigos. Ainda que o conteúdo integral seja lido por menos pessoas, ofazer jornalístico que respalda os feeds de destaques é essencial para a constituição de sua credibilidade e serve de argumento para firmar o lugar essencial do jornalismo em contraponto à diversidade de informações sem "um nome fiador" que figura nos compartilhamentos em mídias sociais.

A hipótese de que são abordados por Le Monde temas de relevância internacional justifica a presença de notícias sobre a seca no Brasil (problema relacionado a aquecimento global e preservação ambiental), sobre possível agressão a membros de tribo indígena (numa visão cultural globalizada, o índio, em especial, merece ser respeitado e preservado) e o Zika vírus (tema que pôs o planeta em alerta com o risco de uma epidemia global). A questão faz pensar que, possivelmente, quando a imprensa trata de outro país é, de fato, de um ponto de vista globalizado que 0 faz. Assim, a resposta sobre quem fala sobre 0 Brasil poderia ser um locutor inserido na globalização que, a rigor, não trata do Brasil em si, mas de aspectos de um mundo globalizado do qual o país faz parte. Seriam, portanto, notícias mais sobre o mundo do que sobre um país estrangeiro.
Quanto aos assuntos relacionados à política interna brasileira, que são recorrentes num período caracterizado por efervescência na política nacional, a hipótese da relevância internacional parece se colar à outra mais trivial e cotidiana do fazer jornalístico, a de que determinados assuntos, por serem impactantes, ainda que para uma população não local, precisam ser tratados como acontecimentos. Precisam acontecer e, em nível de inserção na memória discursiva, é o jornalismo que constrói o acontecimento. Se algo afeta um grande número de pessoas, ou chama atenção pelo exótico, não pode deixar de ser dito.

Se os assuntos são locais para Le Monde (franceses), podem vir categorizados pela temática, a exemplo de Présidentielle (cobertura das eleições francesas). Se 0 assunto é relativo a outro país, é quase uma regularidade que 0 nome desse país - compreendido como "outro" apareça logo no início, para situar o leitor. Quase sempre, isso ocorre com o uso da palavra "Brésil" como uma retranca (rubrique), ou utilizada logo no início do título, ou ainda com o uso da adjetivação "brasileiro/brasileira", a exemplo dos seguintes títulos publicados no mesmo dia (Figuras 2 e 3, acima):

- No Brasil, "a seca agride" (05/05/17, grifo nosso, aspas no original) ${ }^{18}$

- A justiça brasileira condena duramente oito pessoas por apologia ao terrorismo (05/05/17, grifo nosso) ${ }^{19}$ 
A notícia sobre o possível ataque a uma tribo indígena (Figura 5, acima), por sua vez, não enfatizou o Brasil no início do título (o advérbio "no Brasil" foi destinado ao final da frase), transferindo a ênfase principal para o nome 0NU:

- A ONU se alarma com um ataque a uma tribo indígena por proprietários de terra no Brasil $(05 / 05 / 17)^{20}$

A formulação com ênfase para o nome $0 \mathrm{NU}$ reforça a hipótese de que 0 assunto em questão é tratado como algo global, universal, por seu caráter humanitário, dizendo respeito mais ao mundo do que pontualmente ao Brasil. Nessa matéria, lê-se que a ONU citada refere-se ao órgão brasileiro da entidade, mas é o seu nome global que garante 0 peso para 0 destacamento.

0 título do dia 06/05/2017 de Le Monde aponta para 0 fato de que 0 nome Lula é internacionalmente conhecido, já que o nome Brasil é, nesse caso, dispensado pelo jornal na formulação do título. Tal independência do nome Lula é curiosa quando observada a posição que a manchete ocupa na lista, seguida por outros temas que iniciam com a rubrica dos nomes Reino Unido e Estados Unidos (Figura 8):

- Um antigo diretor da Petrobras põe diretamente em causa 0 ex-Presidente Lula ${ }^{21}$

- Reino-Unido: os Tories esmagam o Partido TrabaIhista [Labour Party] e o UKIP nas eleições locais ${ }^{22}$

- Estados Unidos: um policial texano culpado da morte de um adolescente negro ${ }^{23}$

Os dados indicam que, do ponto de vista do jornal, o nome Lula tem mais peso internacional que 0 do Presidente Michel Temer, já que o nome Brasil sempre acompanha notícias relacionadas ao peemedebista. De 19 a 22/5/2017, circularam as seguintes matérias com a retranca "Brasil" no aplicativo:

- Brasil: o presidente Temer recusa a renúncia e pleiteia sua inocência $(18.05 .17)^{24}$

- Brasil: o presidente Michel Temer acusado de obstrução da justiça (19.05.17) ${ }^{25}$

- Brasil: o presidente Michel Temer reclama a suspensão do inquérito que 0 visa $(20.05 .17)^{26}$

No original: "Au Brésil, 'la sécheresse cogne”"

19 No original: "La justice brésilienne condamne lourdement huit personnes pour apologie du terrorisme"

20 No original: "L'ONU s'alarme de l'attaque d'une tribu indienne par des propriétaires terriens au Brésil."

21 No original: "Un ancien directeur de Petrobras met directement em cause l'ex-président Lula"

22 No original: "Royaume-Uni: les tories écrasent le Labour et le UKIP aux élections locales"

23 No original: "Etats-Unis: um policier texan inculpé du meurtre d'un adolescent noir"

24 No original: "Brésil: le président Temer refuse de démissioner et plaide son innocence"

25 No original: "Brésil: le président Michel Temer accusé d'obstruction à la justice"

26 No original: "Brésil: le président Michel Temer réclame la suspension de l'enquête qui le vise" 
A questão sobre o nome Lula foi confirmada na entrevista com o médiateur, que relatou não haver necessidade de referência ao Brasil nesse caso, afirmando que "Lula é como Obama!", ou seja, um nome que não precisa estar colado à sua nacionalidade, já que todos sabem quem é. Sobre esse aspecto, o médiateur avalia que são poucos nomes assim, mundiais. Segundo ele, por exemplo, o nome Merkel (primeira-ministra alemã) tem esse peso na França, dispensando que se diga Alemanha, mas não no mundo todo, o que seriam casos mais raros. 0 nome Lula, inclusive, foi o primeiro mencionado pelo entrevistado ao abordar a cobertura internacional sobre o Brasil: "Um personagem como Lula é muito popular aqui na França, seguimos muito [o que ele faz]. Sua responsabilidade política é reclamada, solicitada. Então, é importante cobrir Lula, o que ele diz. Em todo caso, isso interessa ao público que lê Le Monde" (NOUCHI, 2018 - em entrevista a MORAES). 0 nome "Lula" é um exemplo de fragmento forte de memória discursiva (de teor internacional) sobre o Brasil e, reciprocamente, a repetição em destaque de seu nome contribui para consolidar essa memória.

\section{Considerações finais}

Dentro dos limites deste artigo, demonstramos alguns aspectos das condições de produção do discurso jornalístico na contemporaneidade e como se articulam com a formulação das chamadas de notícias que, no caso, circulam em aplicativos. Esses elementos de destaque influenciam decisivamente na fixação de memória discursiva.

0 aumento de disponibilidade de notícias ocorrido com o desenvolvimento das tecnologias digitais e do jornalismo em rede produz efeitos sobre os discursos, entre os quais a exacerbação do potencial de destacamento. Como defende Maingueneau (2001, 2010 etc.), o midium não se resume a mero suporte, mas impacta os modos de dizer e consequentes efeitos de sentido. Paveau, por sua vez, observa que as tecnologias discursivas produzidas por esses discursos estão longe de ser apenas seus suportes técnicos, representando, mais do que isso, seus elementos constitutivos (2015, p. 320).

0 cruzamento de leituras de teor internacional em diferentes mídias toca num ponto sensível do jornalismo, já que, conforme Grevisse, a aceleração da midiatização internacional imediata, ao conter falhas deontológicas, pode "marcar fortemente os espíritos" (GREVISSE, 2016, p. 19, tradução nossa ${ }^{27}$. Uma vez que a cobertura internacional ocupa um lugar fundamental na construção de identidades, é necessário considerar o vínculo entre o papel do jornalismo e os registros de memória. Vimos que essa memória se mostra de uma maneira (mais) 
fragmentada nas formulações ao modo de listas, o feed de destaques, onde alguns acontecimentos são enfatizados, outros silenciados.

Embora exista tanto o leitor scanner quanto aquele que busca aprofundamento de conteúdo, a existência em si do formato de notícias para aplicativos em dispositivos móveis potencializa a leitura scanner, dada a grande disponibilidade de informação entrecruzada com a atenção dispersa do leitor padrão. Por isso, os efeitos dessa leitura fragmentada são decisivos para a construção de uma memória também fragmentada e em constante movimento. Uma memória que se molda como conjunto de "palavras-chave", como a metáfora de uma nuvem.

Nossa pesquisa aponta a pertinência do conceito de destacamento para a análise de material de aplicativos, cujas características (de produção e leitura) exacerbam a visibilidade dos elementos destacados. 0 feed de destaques, conectado a processos hipertextuais, pode ser compreendido como lugar privilegiado de produção, compactuação e cristalização de memória. Influenciada pelos novos suportes de informação, a memória não só é mais fragmentada, mas também individualizada, a depender do caminho percorrido pelo usuário. A mídia, por sua vez, ainda detém certo controle (quais títulos permanecem no topo dofeed, quais merecem alertas etc.), sua atuação impacta o que será veiculado e retomado com maior frequência. A posição relevante que um título, por exemplo, ocupa no texto é condensadora de discurso, marca posicionamento. Esse "controle" é relativo, por vezes escapa. A memória, então, constitui-se nos vãos entre 0 dito-acontecido, 0 destacado, 0 repetido-retomado, categorias ainda mais moventes diante dos rearranjos tecnológicos da atualidade.

\section{Referências}

ANGERMULLER, Johannes. Análise de discurso pós-estruturalista. As vozes do sujeito na linguagem em Lacan, Althusser, Foucault, Derrida e Sollers. Campinas: Pontes Editores, 2016.

BERTOCCHI, D.; CAMARGO, I.0. de; SILVEIRA, S. C. Possibilidades narrativas em dispositivos móveis. In: CANAVILHAS, J.; SATUFI, I. (Org.). Jornalismo para Dispositivos Móveis: Produção, Distribuição e Consumo. Covilhã: Labcom, 2015. Disponível em: < http://www.labcomifp.ubi.pt/ ficheiros/20150622-201515_jdm_jcanavilhas.pdf $>$.

CANAVILHAS, J.; SATUFI, I. (Org.). Jornalismo para Dispositivos Móveis: Produção, Distribuição e Consumo. Covilhã: Labcom, 2015. Disponível em: < http://www.labcomifp.ubi.pt/ ficheiros/20150622-201515_jdm_jcanavilhas.pdf $>$.

GREVISSE, Benoît. Déontologie du journalisme enjeux éthiques et identités professionnelles. $2 \mathrm{ed}$. Paris, deboeck supérieur, 2016.

MAINGUENEAU, Dominique. Frases sem Texto. São Paulo: Parábola, 2014. Doze conceitos em Análise do Discurso. São Paulo (SP): Editora Parábola, 2010. Cenas da Enunciação. Trad. Sírio Possenti e Maria Cecíla Pérez de Souza-e-Silva. Curitiba (PR): Criar Edições, 2006. Gênese dos Discursos. Curitiba: Criar Edições, 2005. 
Análise de textos de comunicação.

São Paulo, Editora Cortez, 2000.

. Notas de aulas. Curso ministrado para

mestrado na Université Paris-Sorbonne no ano letivo 2017.

MEDINA, C. de A. Notícia: um produto à venda: jornalismo na sociedade urbana e industrial. 2 ed São Paulo, Summus, 1988.

MELLO, A. F.; PASE, A.F.; GOSS, B.M; SOUZA, D.R; PELLANDA, E.C.; SANTOS, F.F; SICA, K. Jornalismo adaptado a novas telas: um estudo da linguagem jornalística nas novas interfaces móveis In: CANAVILHAS, J.; SATUFI, I. (Org.). Jornalismo para Dispositivos Móveis: Produção, Distribuição e Consumo. Covilhã: Labcom, 2015. Disponível em: < http://www.labcomifp.ubi.pt/ ficheiros/20150622-201515_jdm_jcanavilhas.pdf > . MIOLI, T.; NAFRÍA, I. (EDS.). Jornalismo Inovador na América Latina. Austin, Texas: Knight Center for Journalism in the Americas/Open Society Foundations, 2017. Disponível em: < https://knightcenter.utexas.edu/ books/PIPortugues.pdf $>$ Acesso em novembro de 2017.

MOHERDAUI, L. Guia de estilo web: produção e edição de notícias on-line. São Paulo: Senac, 2003.

MORAES, Érika de. De 'Je suis Charlie’ a 'Je suis (...)'

- a circulação de uma fórmula e de uma noção de solidariedade coletiva. Estudos Linguísticos.

São Paulo: v. 45, p. 791-801, 2016.

MORAES, Érika de. Aplicativos de notícias, destacabilidade e efeitos de sentidos: representações de identidades sobre 0 Brasil. Relatório de Pesquisa no Exterior realizada na Université Paris Sorbonne (Paris IV), em Paris, França, sob a supervisão do prof. Dr. Dominique Maingueneau, 2017. FAPESP Processo 2016/18915-3.

NOUCHI, Franck; MORAES, Érika de. Le Monde e a cobertura internacional sobre o Brasil: entrevista com Franck Nouchi, médiateur Le Monde. Revista
Brasileira de Ciências da Comunicação (Intercom). São Paulo: v. 41, p. 199-208, 2018.

PAVEAU, Marie-Anne. Linguagem e moral - uma ética das virtudes discursivas. Campinas: Editora Unicamp, 2015.

PÊCHEUX, Michel. Análise automática do Discurso. In: GADET, F. \& HAK, T. (Org.) Por uma análise automática do discurso: uma introdução à obra de Michel Pêcheux. Trad. Eni P. Orlandi. Campinas (SP): Editora da Unicamp, 1990. (Edição original: 1969).

RADUT-GAGHI, Luciana. "Les appropriations journalistiques". Seminaire presenté à l'École des Hautes Études en Sciences Sociales (EHESS) à Paris, le 12 mai 2017. Organisé par Johannes Angermuller, Josiane Boutet, Marc Glady.

RESENDE, Fernando. 0 jornalismo e suas narrativas: as brechas do discurso e as possibilidades do Encontro. Revista Galáxia. São Paulo: n. 18, p. 31-43, dez. 2009. RICOEUR, P. Discours et communicacion. In: Cahier de L'Herne Ricoeur. Paris: Editions de L'Herne, n. 81. RING00T, Roselyne. Analyser le discours de presse. Paris: Armand Colin, 2014. 


\section{The detachment in news applications and the production of discursive memory}

\section{Abstract}

This article analyzes discursively the functioning of journalistic coverage in two news applications: one national (UOL, linked to the Folh a group) and another international (Le Monde). With the theoretical-methodological support of the French Discourse Analysis, the main objective is to demonstrate how the current mode of circulation of news produces effects on the registers that crystallize themselves in the discursive memory. The data analyzed demonstrate that the characteristics of the contemporary discursiveness, with emphasis on detachment, contribute to the production of fragmented discursive memories, but still with some control by the media.

\section{Keywords}

Applications. Detachment. Discursive memory.

\section{El destacamento en aplicaciones} de noticias y la producción de memoria discursiva

\section{Resumen}

Este artículo analiza discursivamente el funcionamiento de la cobertura periodística en dos aplicaciones para dispositivos móviles: un nacional (UOL, vinculado al grupo Folha) y un internacional (Le Monde). Con el respaldo teórico-metodológico del Análisis del Discurso de línea francesa, el objetivo principal es demostrar cómo el modo actual de circulación de las noticias produce efectos sobre los registros que se cristalizan en la memoria discursiva. Los datos analizados demuestran que las características de la discursividad contemporánea, con énfasis en el destacamento, contribuyen a la producción de memorias discursivas fragmentadas, aún así con cierto control por parte de los medios.

\section{Palabras-clave}

Aplicaciones. Destacamento. Memoria Discursiva. 


\section{Expediente}

A revista E-Compós é a publicação científica em formato eletrônico da Associação Nacional dos Programas de Pós-Graduação em Comunicação (Compós). Lançada em 2004, tem como principal finalidade difundir a produção acadêmica de pesquisadores da área de Comunicação, inseridos em instituições do Brasil e do exterior.

\section{E-COMPÓS I www.e-compos.org.br I E-ISSN 1808-2599}

Revista da Associação Nacional dos Programas de Pós-Graduação em Comunicação. Brasília, v.21, n.3, set/dez. 2018. A identificação das edições, a partir de 2008, passa a ser volume anual com três números. Indexada por Latindex I www.latindex.unam.mx

\section{CONSELHO EDITORIAL}

Ada Cristina Machado Silveira, Universidade Federal de Santa Maria, Brasi Alda Cristina Silva da Costa, Universidade Federal do Pará, Brasil Alfredo Luiz Paes de Oliveira Suppia, Universidade Estadual de Campinas, Brasil Ana Carolina Rocha Pessôa Temer, Universidade Federal de Goiás, Brasil Ana Regina Barros Rego Leal, Universidade Federal do Piauí, Brasil André Luiz Martins Lemos, Universidade Federal da Bahia, Brasil Angela Cristina Salgueiro Marques, Universidade Federal de Minas Gerais, Brasil Ângela Freire Prysthon, Universidade Federal de Pernambuco, Brasil Anna Cristina Pertierra, Western Sidney University, Austrália Antonio Carlos Hohlfeldt, Pontifícia Universidade Católica do Rio Grande do Sul, Brasi Arthur Ituassu, Pontifícia Universidade Católica do Rio de Janeiro, Brasil Bruno Campanella, Universidade Federal Fluminense, Brasil Bushra Hameedur Rahman, University of the Punjab, Paquistão, Paquistão Cárlida Emerim, Universidade Federal de Santa Catarina, Brasil Carlos Del Valle Rojas, Universidad de La Frontera, Chile Carlos Eduardo Franciscato, Universidade Federal de Sergipe, Brasil Cláudio Novaes Pinto Coelho, Faculdade Cásper Líbero, Brasil Danilo Rothberg, Universidade Estadual Paulista, Brasil Denise Tavares, Universidade Federal Fluminense, Brasil Diógenes Lycarião, Universidade Federal do Ceará, Brasil Dóris Martínez Vizcarrondo, Universidad de Puerto Rico Mayagüez, Porto Rico Eduardo Vicente, Universidade de São Paulo, Brasil

Eliza Bachega Casadei, Escola Superior de Propaganda e Marketing - SP, Brasil Elvira Gomes dos Reis Freitas, Universidade de Cabo Verde, Cabo Verde Eneus Trindade, Universidade de São Paulo, Brasil Erick Felinto de Oliveira, Universidade do Estado do Rio de Janeiro, Brasil Erick Torrico, Universidad Andina Simón Bolívar, Bolívia, Bolívia Erly Vieira Júnior, Universidade Federal do Espírito Santo, Brasil Fabio La Rocca, Université Paul-Valéry Montpellier 3, França Fernando Firmino da Silva, Universidade Federal da Paraíba, Brasil Francisco de Assis, FIAM-FAAM Centro Universitário, Brasil Francisco Elinaldo Teixeira, Universidade Estadual de Campinas, Brasil Francisco Gilson Rebouças Pôrto Junior, Universidade Federal do Tocantins, Brasil Francisco Sierra Caballero, CIESPAL, Equador Frederico de Mello Brandão Tavares, Universidade Federal de Ouro Preto, Brasil Gabriela Reinaldo, Universidade Federal do Ceará, Brasil Germán Rey Beltrán, Universidad Nacional de Colombia, Colômbia Gilson Vieira Monteiro, Universidade Federal do Sul da Bahia, Brasil Gustavo Daudt Fischer, Universidade do Vale do Rio dos Sinos, Brasil Gustavo Hernández Díaz, Universidad Central de Venezuela, Venezuela Heidi Figueroa Sarriera, Universidad de Puerto Rico, Porto Rico Ignacio Aguaded, Universidad Huelva, Espanha Inesita Soares de Araújo, FIOCRUZ, Brasil Itania Maria Mota Gomes, Universidade Federal da Bahia, Brasil Jiani Adriana Bonin, Universidade do Vale do Rio dos Sinos, Brasi João Carlos Ferreira Correia, Universidade da Beira Interior, Portugal Jonathan Cohen, University of Haifa, Israel José Afonso da Silva Junior, Universidade Federal de Pernambuco, Brasil José Luiz Aidar Prado, Pontifícia Universidade Católica de São Paulo, Brasil Josette Maria Monzani, Universidade Federal de São Carlos, Brasil Juçara Gorski Brittes, Universidade Federal de Ouro Preto, Brasil Julián Durazo Hermann, Université du Québec à Montreal, Canadá Juliana Freire Gutmann, Universidade Federal da Bahia, Brasil
Karla Yolanda Covarrubias, Universidad de Colima, México Laura Loguercio Cánepa, Universidade Anhembi Morumbi, Brasil Leonel Azevedo de Aguiar, Pontifícia Universidade Católica do Rio de Janeiro, Brasil Leticia Cantarela Matheus, Universidade do Estado do Rio de Janeiro, Brasil Ling Chen, Hong Kong Baptist University, China Luciana Coutinho Souza, Universidade de Sorocaba, Brasil Marcel Vieira Barreto Silva, Universidade Federal da Paraíba, Brasil Marcia Tondato, Escola Superior de Propaganda e Marketing, Brasil Márcio Souza Gonçalves, Universidade do Estado do Rio de Janeiro, Brasil Maria Ataide Malcher, Universidade Federal do Pará, Brasil Maria das Graças Pinto Coelho, Universidade Federal do Rio Grande do Norte, Brasi Maria Elena Hernández Ramirez, Universidad de Guadalajara, México Maria Elisabete Antonioli, Escola Superior de Propaganda e Marketing - SP, Brasil Maria Teresa Quiroz, Universidad de Lima, Peru Marialva Carlos Barbosa, Universidade Federal do Rio de Janeiro, Brasil Marina Poggi, Universidad Nacional de Quilmes, Argentina Marli Santos, Faculdade Cásper Líbero, Brasil Mateus Yuri Passos, Universidade Metodista de São Paulo, Brasil Mauricio Mario Monteiro, Universidade Anhembi Morumbi, Brasil, Brasil Mayka Castellano, Universidade Federal Fluminense, Brasil Mirta Varela, Universidad de Buenos Aires, Argentina

Mozahir Salomão Bruck, Pontifícia Universidade Católica de Minas Gerais, Brasil Neyla Graciela Pardo Abril, Universidad Nacional de Colombia, Colômbia Nísia Martins Rosario, Universidade Federal do Rio Grande do Sul, Brasil Olga Guedes Bailey, Nottingham Trent University, Reino Unido Paolo Demuru, Universidade Paulista, Brasil

Paolo Peverini, LUISS, Itália

Paško Bilić, Institute for Development and International Relations, Croácia Paula Melani Rocha, Universidade Estadual de Ponta Grossa, Brasil Potiguara Mendes Silveira Jr, Universidade Federal de Juiz de Fora, Brasil Rafael Cardoso Sampaio, Universidade Federal do Paraná, Brasil Rafael Tassi Teixeira, Universidade Tuiuti do Paraná, Brasil Regiane Lucas de Oliveira Garcêz, Universidade Federal de Minas Gerais, Brasil Regiane Regina Ribeiro, Universidade Federal do Paraná, Brasil Renata Pitombo Cidreira, Universidade Federal do Recôncavo da Bahia, Brasil Renato Essenfelder, Escola Superior de Propaganda e Marketing, Brasil Roberto Elísio dos Santos, Universidade Municipal de São Caetano do Sul, Brasil Robson Borges Dias, Universidade Católica de Brasília (UCB), Brasil Rodolfo Rorato Londero, Universidade Estadual de Londrina, Brasil Rosario Sanchéz Vilela, Universidad Católica del Uruguay, Uruguai Roseli Figaro, Universidade de São Paulo, Brasil Saima Saeed, Jamia Millia Islamia, India Sara Brandellero, Leyden University, Holanda Simone Maria Andrade Pereira de Sá, Universidade Federal Fluminense, Brasil Sônia Caldas Pessoa, Universidade Federal de Minas Gerais, Brasil Sun Sun Lim, Singapore University of Technology and Design, Singapura Tatiana Oliveira Siciliano, Pontifícia Universidade Católica do Rio de Janeiro, Brasil Thaïs de Mendonça Jorge, Universidade de Brasília, Brasil Valquiria Michela John, Universidade Federal do Paraná, Brasil Vicky Mayer, Tulane University, Estados Unidos da América do Norte Yamile Haber Guerra, Universidad de Oriente, Cuba 


\section{CONSELHO CIENTÍFICO}

Cristiane Freitas Gutfreind, Pontifícia Universidade Católica do Rio Grande do Sul, Brasil I Eduardo Antonio de Jesus, Universidade Federal de Minas Gerais, Brasil I Eduardo Morettin, Universidade de São Paulo, Brasil I Irene de Araújo Machado, Universidade de São Paulo, Brasil

\section{COMISSÃO EDITORIAL}

Igor Pinto Sacramento, Universidade Federal do Rio de Janeiro, Brasil I Kelly Cristina de Souza Prudencio, Universidade Federal do Paraná, Brasil | Miriam de Souza Rossini, Universidade Federal do Rio Grande do Sul, Brasil

\section{EDITORES ASSOCIADOS}

Rafael Grohmann, Faculdade Cásper Líbero, Brasil I Thaiane Moreira de Oliveira, Universidade Federal Fluminense, Brasil

\section{CONSULTORES AD HOC}

Ada Machado, Universidade Federal de Santa Maria, Brasil | Ana Carolina Escosteguy, Universidade Federal de Santa Maria, Brasil | Andrea França, Pontifícia Universidade Católica do Rio de Janeiro, Brasil | Ariane Holzbach, Universidade Federal Fluminense, Brasil | Benjamim Picado, Birkbeck College, Inglattera | Bruno Souza Leal, Universidade Federal de Minas Gerais, Brasil I Eduardo Morettin, Universidade de São Paulo, Brasil I Felipe Trotta, Universidade Federal Fluminense, Brasil | Francisco Rüdiger, Pontifícia Universidade Católica do Rio Grande do Sul, Brasil | Gislene da Silva, Universidade Federal de Santa Catarina, Brasil | Inês Vitorino, Universidade Federal do Ceará, Brasil I Isaltina Gomes, Universidade Federal de Pernambuco, Brasil I Jairo Ferreira, Universidade do Vale do Rio dos Sinos, Brasil I Karina Janz, Universidade Estadual de Ponta Grossa, Brasil | Kati Caetano, Universidade Tuiuti do Paraná, Brasil | Lilian França, Universidade Federal do Sergipe, Brasil | Liziane Guazina, Universidade de Brasília, Brasil I Márcio de Vasconcellos Serelle, Pontifícia Universidade Católica de Minas Gerais, Brasil I Marta Maia, Universidade Federal de Ouro Preto, Brasil I Maurício de Bragança, Universidade Federal Fluminense, Brasil I Nina Velasco e Cruz, Universidade Federal de Pernambuco, Brasil | Norval Baitello Jr., Pontifícia Universidade Católica de São Paulo, Brasil | Pedro Guimarães, Universidade do Estado do Rio de Janeiro, Brasil | Priscilla Perazzo, Universidade Municipal de São Caetano do Sul, Brasil I Sofia Zanforlin, International Association of Media and Communication Research, Estados Unidos I Talitha Ferraz, Escola Superior de Propaganda e Marketing, Brasil I Tattiana Teixeira, Universidade Federal de Santa Catarina, Brasil I Victa de Carvalho Pereira da Silva, Universidade Federal do Rio de Janeiro, Brasil

\section{EQUIPE DE EDITORAÇÃO}

ASSISTENTE EDITORIAL Marcio Telles I REVISÃO DE TEXTOS Fátima Áli | EDITORAÇÃO ELETRÔNICA Roka Estúdio

COMPÓS I www.compos.org.br

Associação Nacional dos Programas de Pós-Graduação em Comunicação

Presidente

Marco Roxo

Programa de Pós-Graduação em Comunicação - UFF

marcos-roxo@uol.com.br

Vice-Presidente

Isaltina Gomes

Programa de Pós-Graduação em Comunicação - UFPE

isaltina@gmail.com

Secretária-Geral

Gisela Castro

Programa de Pós-Graduação em Comunicação

e Práticas de Consumo - ESPM

castro.gisela@gmail.com

CONTATO I revistaecompos@gmail.com 